\title{
Silica Derived from Burned Rice Hulls
}

\author{
M.F. de Souza*, W.L.E. Magalhães, M.C. Persegil \\ Department of Physics and Materials Science - Center for Optics and Photonics \\ CEPOF - Institute of Physics of São Carlos, USP
}

Received: February 01, 2002; Revised: July 21, 2002

\begin{abstract}
Three new processes to obtain silica having high specific surface area from burned pre-treated rice hulls are presented and discussed. These procedures allow for the simultaneous recovery of biomass energy and the production of high quality silica at thermoelectric plants, without the risk of using corrosive substances in the burning process. The first method involves treatment of the hull with hot organic acid solutions before burning, the second with boiling water, both using an autoclave at temperatures close to $150{ }^{\circ} \mathrm{C}$, while the third method renders the hull fragile by treating it at $250{ }^{\circ} \mathrm{C}$ and reducing it to a fine powder before burning. The first two methods result in white amorphous silica that can show $500 \mathrm{~m}^{2} / \mathrm{g}$ of specific surface area. The third method, which does not remove the alkaline elements from the hull, produces an amorphous gray carbon-free powder whose specific surface area can be as high as $250 \mathrm{~m}^{2} / \mathrm{g}$. An investigation of the specific surface area of the prepared silica indicates the alkaline elements are not mixed with silica in the hulls or combined as insoluble compounds. A comparison is made of these processes and the dissolution of silica by sodium hydroxide solutions is discussed.
\end{abstract}

Keywords: amorphous silica, nanosilica, rice hull, energy, thermoelectric plants

\section{Introduction}

Rice hulls are known to have a relatively high content of inorganic compounds representing approximately $20 \mathrm{wt} \%$ of the dry hull, $94 \mathrm{wt} \%$ of which is silica. The remaining 6 wt $\%$ consists of $\mathrm{K}_{2} \mathrm{O}, \mathrm{CaO}, \mathrm{MgO}, \mathrm{MnO}, \mathrm{Al}_{2} \mathrm{O}_{3}, \mathrm{P}_{2} \mathrm{O}_{5}, \mathrm{SiO}_{2}$, in decreasing concentrations ${ }^{1,2}$ and is hereinafter referred to as impure elements because they change the properties of the silica that can be produced from the hull. The main organic compounds in the dry hull are cellulose and hemicellulose, $50 \mathrm{wt} \%$, and lignin, $26 \mathrm{wt} \%$, with the remaining $4 \mathrm{wt} \%$ representing other organic compounds such as oil, proteins, etc. The organic and inorganic compositions depend on several factors, including weather, soil and plant variety. The amorphous and white silica that can be extracted from the hull and the straw of the rice plant may possess a very high specific surface area, SSA. The wt $\%$ composition of the rice straw (including the leaves) is 13.1 silica, 37.4 cellulose, 44.9 hemi-cellulose and 4.9 lignin $^{1}$. The straw/hull weight ratio is close to $3.6^{3}$ and the world's annual rice output is around 300 million tons, representing a potential production of almost 40 million tons of silica from processed hulls and straw. The potential to extract high quality silica from these residues has attracted the attention of several researchers ${ }^{4-8}$.

Although silica with high SSA can potentially be extracted by microbiological degradation because it excludes calcination, the hull's organic compounds are known to biodegrade only after long periods of time ${ }^{9,10}$, rendering this process an unviable alternative. Therefore, the processes currently employed to separate silica from organic components involve burning rice hulls at temperatures above $\approx 450{ }^{\circ} \mathrm{C}$. During burning, the impure elements, especially alkaline and alkaline earth oxides, strongly reduce the silica's SSA. Calcium, magnesium, potassium, sodium and aluminum oxides, all present in the hull, react at high temperatures and long soaking times with part of the silica to produce a kind of soda lime glass ${ }^{7,11}$, in which sodium is replaced by potassium, which reduces the residue's SSA to close $1.0 \mathrm{~m}^{2} / \mathrm{g}{ }^{12}$. This point will be further discussed in section 3.4.

The sintering effect of the glassy phase can be very effective in reducing the SSA if the hull is burned at uncontrolled high temperatures and without previous treatment. ${ }^{7}$ Crystalline phases, mainly cristobalite, develop during long

*e-mail: mfs@if.sc.usp.br 
sintering times at high temperatures, and carbon remains inside silica particles, turning the residue black ${ }^{12-14}$. The development of crystalline phases renders silica powder potentially dangerous for the human respiratory system ${ }^{15}$.

Treatment of the hull with an acid solution at the boiling temperature for several hours, as was done by Amick ${ }^{6}$ and later extended by Real et al. ${ }^{4}$, removes a large fraction of the impure elements that would otherwise contribute to the formation of a glassy phase. The latter authors obtained silica with high SSA, i.e., approximately $250 \mathrm{~m}^{2} / \mathrm{g}$, and their TEM (transmission electron microscopy) analyses revealed that the ultimate particle size of their silica powders was close to $10 \mathrm{~nm}$. This specific surface area and ultimate particle size of the silica indicate that rice hull is a possible low cost source for nanosize silica powders, or at least a very reactive silica powder. A more effective inorganic acid treatment is achieved by increasing the temperature of the water acid solution to $160^{\circ} \mathrm{C}$ or higher for $30 \mathrm{~min}$, using an autoclave, as demonstrated by de Souza et al. ${ }^{5,8}$. Under such conditions, the production of amorphous white silica with a SSA as high as $480 \mathrm{~m}^{2} / \mathrm{g}$ has been reported.

These findings suggest that the removal of alkaline elements by acid treatment before the rice hull is burned is a necessary step in the production of high SSA silica because it eliminates or reduces the glass-sintering phase. Indeed, acid treatment is the best process to produce high purity silica. This paper demonstrates that high SSA silica (lower than $250 \mathrm{~m}^{2} / \mathrm{g}$ ) can be obtained without removing the impure elements before burning. Moreover, the hull can be pretreated with hot water to remove the impure elements. This procedure allows for the simultaneous recovery of biomass energy and the production of high quality silica at thermoelectric plants, without the risk of using corrosive substances in the burning process. Acid treatments may also be appropriate, provided organic acids such as acetic and citric acid are used, since they decompose into water and carbon oxide in the burning process.

An investigation was also made of the sodium hydroxide attack of the as received hull and hull ash produced at thermoelectric plants.

\section{Experimental}

Rice hulls (Cultivar IRGA 409-407) from the region of São Borja, RS, Brazil, were used in this work. Five different processes, named A, B, C, D and E, were used to prepare the silica, the first two solely for purposes of comparison of the silica properties they produce. Therefore, only the $\mathrm{C}, \mathrm{D}$ and $\mathrm{E}$ processes are original silica preparation procedures of high SSA considered in this paper. In process A (Table 1), as received rice hulls were burned in an electric furnace at $900{ }^{\circ} \mathrm{C}$ under atmospheric pressure for $360 \mathrm{~min}$. Process $\mathrm{B}$ consisted of the following steps, already described in references ${ }^{5,8}: 1$ - pretreatment of the hulls in an aqueous solution with $5.0 \mathrm{wt} \%$ of hydrochloric acid at $150{ }^{\circ} \mathrm{C}$ for $1.0 \mathrm{~h}$ in an autoclave; 2 - successive washing with distilled water until the last rinse reached $\mathrm{pH}=6.0 ; 3$ - the treated hull was dried and burned at $500^{\circ} \mathrm{C}$ for $2.0 \mathrm{~h} ; 4$ - the resulting white powder was dry ball milled with zirconia balls in plastic bottles. Process $\mathrm{C}$ was the same as B, but the hydrochloric acid was replaced by acetic acid or citric acid and washing was done twice with tap water. Processes DI to DIII consisted of treating the hulls with hot water at temperatures above $100{ }^{\circ} \mathrm{C}$ (preferentially $150^{\circ} \mathrm{C}$ ) in an autoclave, followed by washing one, two or three times, burning at $700{ }^{\circ} \mathrm{C}$ for $120 \mathrm{~min}$ and milling, see Table 1 .

Process $\mathrm{E}$ consisted of a combination of several steps described in Table 1, all involving treatment of the as received hulls at $250{ }^{\circ} \mathrm{C}$ for $30 \mathrm{~min}$ to transform them into black fragile bodies, followed by dry ball milling in a plastic jar with zirconia balls for 30 min. The black powder resulting from this stage contained $40 \%$ of inorganic compounds and had an average particle size of $20.0 \mu \mathrm{m}$. Processes EI to EIII consisted of treating the black powder (or the fragile black hull) before calcination. In the procedure EI this powder was treated with a $5.0 \mathrm{wt} \%$ boiling solution of hydrochloric (acetic or citric) acid under atmospheric pressure, followed by washing with distilled water at RT to final $\mathrm{pH}=6.0$ and calcining at $700{ }^{\circ} \mathrm{C}$ for $360 \mathrm{~min}$. Procedure EII treated the black powder with boiling tap water for $120^{\circ} \mathrm{C}$, followed by calcination at $700^{\circ} \mathrm{C}$ for $120 \mathrm{~min}$. Procedure EIII treated the same powder with RT water for 120 min, followed by burning at $700{ }^{\circ} \mathrm{C}$ for $360 \mathrm{~min}$. The acid, hot water and cold water treatments served to decrease the concentration of impure elements ( $\mathrm{K}, \mathrm{Ca}, \mathrm{Mn}$, etc.) in the black powder. Alternatively, the fragile hull can be subjected to the same treatment before milling. In processes EIV to EX, also described in Table 1, neither the black powder nor the resulting silica were subjected to any chemical treatment; only the calcination time and temperature were varied. The silica resulting from the burning step in processes EXI and EXII was treated, respectively, with boiling water and a boiling acid solution, both under atmospheric pressure.

The resulting silica powders were characterized by their XRD pattern (Model RU200B, Rigaku, Japan), BET specific surface area (ASAP 2000, Micromeritics, USA), particle size distribution (CAPA 700, Horiba, Japan) and chemical composition by Inductively Coupled Plasma (ICP-AES, Thermal Jarrell Ash, England).

The extraction of silica by chemical attack of a sodium hydroxide solution, named process $\mathrm{F}$, was carried out as follows. As received rice hulls were boiled in sodium hydroxide solutions ( 1.51 of water for $60 \mathrm{~g}$ of hull) for $1.0 \mathrm{~h}$. The hydroxide concentrations were chosen so as to pro- 
Table 1. Chemical and physical preparation steps to extract silica from rice hulls (S. Borja, RGS, Brazil, cultivator IRGA 409-407) through processes A to EIII.

\begin{tabular}{|c|c|c|c|c|c|c|c|c|c|c|c|c|}
\hline Proc. & $\mathrm{T} 1$ & $\mathrm{~T} 2$ & T3 & $\mathrm{T} 4$ & T5 & T6 & $\mathrm{T} 7$ & $\mathrm{~T} 8$ & T9 & T10 & T11 & T12 \\
\hline A & - & - & - & - & - & - & - & 900 & 360 & - & - & $\mathrm{X}$ \\
\hline B & $\mathrm{X}$ & - & - & - & - & - & $\mathrm{X}$ & 500 & 120 & - & - & $\mathrm{X}$ \\
\hline $\mathrm{C}$ & Ac. & - & - & - & - & $\mathrm{xx}$ & - & 700 & 120 & - & - & - \\
\hline DI & - & $\mathrm{x}$ & - & - & - & $\mathrm{x}$ & - & 700 & 120 & - & - & $\mathrm{x}$ \\
\hline DII & - & $\mathrm{xx}$ & - & - & - & $\mathrm{xX}$ & - & 700 & 120 & - & - & $\mathrm{x}$ \\
\hline DIII & - & XXX & - & - & - & $\mathrm{XXX}$ & - & 700 & 120 & - & - & $\mathrm{X}$ \\
\hline EI & - & - & $\mathrm{X}$ & $\mathrm{X}$ & - & - & $\mathrm{X}$ & 700 & 360 & - & - & - \\
\hline EII & - & - & $\mathrm{x}$ & - & $\mathrm{x}$ & - & - & 700 & 120 & - & - & - \\
\hline EIII & - & - & $\mathrm{x}$ & - & - & $\mathrm{x}$ & - & 700 & 360 & - & - & - \\
\hline EIV & - & - & $\mathrm{x}$ & - & - & - & - & 700 & 360 & - & - & - \\
\hline EV & - & - & $\mathrm{x}$ & - & - & - & - & 700 & 240 & - & - & - \\
\hline EVI & - & - & $\mathrm{x}$ & - & - & - & - & 500 & 360 & - & - & - \\
\hline EVII & - & - & $\mathrm{x}$ & - & - & - & - & 500 & 90 & - & - & - \\
\hline EVIII & - & - & $\mathrm{x}$ & - & - & - & - & 500 & 30 & - & - & - \\
\hline EIX & - & - & $\mathrm{x}$ & - & - & - & - & 700 & 90 & - & - & - \\
\hline $\mathrm{EX}$ & - & - & $\mathrm{x}$ & - & - & - & - & 700 & 10 & - & - & - \\
\hline EXI & - & - & $\mathrm{x}$ & - & - & - & - & 500 & 90 & $\mathrm{x}$ & - & - \\
\hline EXII & - & - & $\mathrm{x}$ & - & - & - & - & 500 & 90 & - & $\mathrm{X}$ & - \\
\hline
\end{tabular}

$\mathrm{T} 1$ - Treatment of rice hulls with an aqueous solution of $5.0 \mathrm{wt} \%$ of hydrochloric (acetic) acid at $150{ }^{\circ} \mathrm{C}$ for $1.0 \mathrm{~h}$ in an autoclave; $\mathrm{T} 2$ Treatment of rice hulls with water at $150{ }^{\circ} \mathrm{C}$ in an autoclave for $60 \mathrm{~min}$; T3 - Calcination of hulls for 60 min at $250{ }^{\circ} \mathrm{C}$, followed by ball milling for $30 \mathrm{~min}$, average particle size of $20.0 \mathrm{~mm}$. T4- Treatment with $5.0 \mathrm{wt} \%$ of hydrochloric acid solution, boiling under atmospheric pressure for $120 \mathrm{~min}$; T5 - Treatment with boiling water, under atmospheric pressure, for $120 \mathrm{~min}$; T6 -Washing at room temperature, RT, tap water for $120 \mathrm{~min}$; $\mathrm{T} 7$ - washing with distilled water to final $\mathrm{pH}=6.0$; $\mathrm{T} 8$ - Calcination temperature, ${ }^{\circ} \mathrm{C}$; $\mathrm{T} 9$ - Calcination time, min; T10 - Silica treatment with a boiling water solution of $2.0 \mathrm{wt} \% \mathrm{HCl}$, under atmospheric pressure; T11 - Silica treatment with a boiling water solution of $10.0 \mathrm{wt} \% \mathrm{HCl}$, under atmospheric pressure; T12 - Dry ball milling for $1.0 \mathrm{~h}$. xx and xxx holds for repetition of the step two and three times, respectively.

duce $\mathrm{SiO}_{2} / \mathrm{Na}_{2} \mathrm{O}$ molar ratios of 0.3 to 3.2. Following the hydroxide attack, the remaining hull matter was filtered from the hydroxide solution and washed several times in water until $\mathrm{pH}=7$ was reached, then dried at $100^{\circ} \mathrm{C}$, weighed, burned at $800^{\circ} \mathrm{C}$ and the final residue weighed to measure the remaining silica.

\section{Results and Discussion}

\subsection{Processes $A$ and $B$}

The effect of impurities on the properties of burned rice hull residue can be evaluated by comparing the composition, surface specific area, color and crystallinity of the prepared silica by the five processes, A to E (see Tables 1 for process and 2 for silica properties). Process A reproduces the common practice of quickly burning the hulls to produce heat and was studied by $\mathrm{Hanna}^{7}$ and Krishnarao et $a l .{ }^{14}$. The untreated hull was burned for long periods at high temperatures, producing a black residue with a low SSA and high crystallinity caused by the presence of cristobalite (see Fig. 1). In this process, amorphous silica was partially

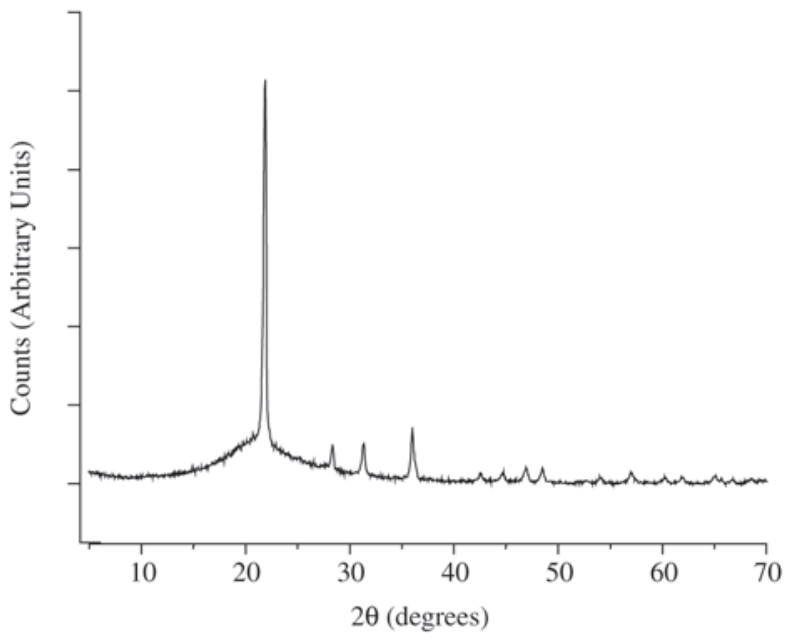

Figure 1. XRD pattern (arbitrary units) of the powder produced by process $1 \mathrm{~A}$. All the peaks are well described by the cristobalite pattern (JCPDS, PDF\#39-1425) superimposed on a broad background caused by the remaining amorphous phase 
Table 2. Chemical analysis, wt\%, and physical properties of the silica prepared by the A, B, C, D and E processes.

\begin{tabular}{lcccccccccccc}
\hline Process & $\mathrm{Si}$ & $\mathrm{K}$ & $\mathrm{Ca}$ & $\mathrm{Mn}$ & $\mathrm{Mg}$ & $\mathrm{Na}$ & $\mathrm{Al}$ & $\mathrm{P}+\mathrm{S}$ & Color & PS & Str & SSA \\
\hline A & 94.0 & 2.2 & 1.3 & 0.7 & 0.4 & 0.1 & 0.5 & 0.8 & black & 10 & crystall. & 2 \\
$\mathrm{~B}$ & 99.5 & 0.0 & 0.0 & 0.0 & 0.0 & 0.0 & 0.1 & 0.4 & white & 1.5 & amorph. & 490 \\
$\mathrm{C}$ & 99.3 & 0.0 & 0.0 & 0.0 & 0.0 & 0.0 & 0.3 & 0.4 & white & 1.5 & amorph & 440 \\
DI & 97.6 & 0.0 & 0.4 & 0.2 & 0.4 & 0.0 & 0.5 & 0.7 & white-gray & 3.0 & amorph & 170. \\
DII & 98.8 & 0.0 & 0.0 & 0.1 & 0.1 & 0.0 & 0.5 & 0.6 & white & 3.0 & amorph & 250 \\
DIII & 99.1 & 0.0 & 0.0 & 0.0 & 0.0 & 0.0 & 0.4 & 0.5 & white & 3.0 & amorph & 320 \\
EI & 98.9 & 0.0 & 0.0 & 0.1 & 0.0 & 0.0 & 0.5 & 0.6 & white & 1.0 & amorph. & 250 \\
EII & 96.6 & 1.0 & 0.6 & 0.4 & 0.2 & 0.1 & 0.5 & 0.6 & grayish & 1.5 & amorph. & 110 \\
EIII & 96.0 & 1.3 & 0.7 & 0.5 & 0.2 & 0.1 & 0.5 & 0.7 & grayish & 1.5 & amorph. & 78 \\
EIV & 94.0 & 2.2 & 1.3 & 0.7 & 0.4 & 0.1 & 0.5 & 0.8 & gray & 7.0 & amorph. & 19 \\
EV & 94.0 & 2.2 & 1.3 & 0,7 & 0.4 & 0.1 & 0.5 & 0.8 & gray & 2.0 & amorph. & 55 \\
EVI & 94.0 & 2.2 & 1.3 & 0.7 & 0.4 & 0,1 & 0.5 & 0.8 & gray & 1.5 & amorph. & 110 \\
EVII & 94.0 & 2.2 & 1.3 & 0.7 & 0.4 & 0.1 & 0.5 & 0.8 & gray & 1.5 & amorph & 200 \\
EVIII & 94.0 & 2.2 & 1.3 & 0.7 & 0.4 & 0.1 & 0.5 & 0.8 & gray & 1.5 & amorph & 220 \\
EIX & 94.0 & 2.2 & 1.3 & 0.7 & 0.4 & 0.1 & 0.5 & 0.8 & gray & 1.5 & amorph. & 105 \\
EX & 94.0 & 2.2 & 1.3 & 0.7 & 0.4 & 0.1 & 0.5 & 0.8 & gray & 1.5 & amorph. & 130 \\
EXI & 96.6 & 1.0 & 0.6 & 0.4 & 0.2 & 0.1 & 0.5 & 0.6 & grayish & 1.5 & amorph. & 135 \\
EXII & 98.0 & 0.0 & 0.0 & 0.2 & 0.1 & 0.1 & 0.5 & 0.6 & white-gray & 1.2 & amorph. & 145 \\
\hline
\end{tabular}

$\mathrm{SSA}=$ specific surface area, $\mathrm{m}^{2} / \mathrm{g} ; \mathrm{PS}=$ average particle size, $\mathrm{mm} ; \mathrm{Str}=$ crystalline structure, $\mathrm{XRD}$.

converted to a crystalline form of silica, crystobalite. The properties of this type of residue are very similar to the residues produced in thermoelectric plants or by the burning of hulls to produce hot air to dry rice grains. The residue's black color can be significantly reduced only if heattreated at temperatures above $1100{ }^{\circ} \mathrm{C}$ for over $120 \mathrm{~min}$, although a grayish color still remains due to a low concentration of manganese oxide. Table 2 shows that the silicarich residue contains impure elements in the same concentration as those in the hull, and the lowest SSA in the table: $2 \mathrm{~m}^{2} / \mathrm{g}$.

In the process $\mathrm{B}$, the impure elements were almost completely removed before burning, resulting in a white amorphous silica with high SSA, $490 \mathrm{~m}^{2} / \mathrm{g}$. This process, which includes acid treatment of the hull, is the best route as far as silica purity and high SSA are concerned, and has been discussed in earlier publications ${ }^{4-6,8}$. Table 2 , line B shows that impurities such as potassium, sodium, calcium, magnesium and manganese were removed to less than $0.1 \mathrm{wt} \%$, while aluminum was significantly reduced and a high percentage of sulfur and phosphorus still remained. These are the results that can be expected from acid treatment, i.e., the alkaline elements are more easily removed than the acidic ones. However, the purity can be improved by additional acid treatments and washing with deionized water, while the SSA can be increased by reducing the burning time. Processes C, D and E are new approaches for silica extraction, which were developed aiming at their use in thermo- electric plants without the use of chemicals, which might contribute to greater corrosion.

A comparison of the silica produced by processes A and B shows the strong effect the impure elements exert not only on the silica's purity but also on its SSA, color and crystallinity. The black color of the residue produced by the process A is attributed to black carbon grains occluded in the residue particles ${ }^{7,14}$.

\subsection{Process $C$}

Organic acids such as acetic or citric acid, which are used in process $\mathrm{C}$, effectively remove alkaline impurities and manganese, as in the case of process $\mathrm{B}$, in which strong inorganic acids are used, although the removal of aluminum, sulfur and phosphorus is less effective, see Table 2, line C. The advantage of process $\mathrm{C}$ is that acids are used, which, in the calcination step, react with oxygen to produce $\mathrm{CO}_{2}$ and water, thus providing greater protection against corrosion, including that of the autoclave. Another outcome of organic acid treatment is the formation of esters, which result from the reaction between acetic acid and rice hull oil. Because ester is water insoluble and less dense, it floats on the surface of the water in the autoclave or may be expelled from the autoclave, together with water vapor, through the highpressure safety valve.

\subsection{Process $D$}

Boiling water, at temperatures above $100{ }^{\circ} \mathrm{C}$, also re- 
moves alkaline elements and even manganese (see lines DI to DIII in Table 2) but is less efficient than acid solutions under the same conditions. No substance other than water is used in this process; therefore, it is not only the best process for corrosion prevention but also simultaneously reduces the concentration of impure elements in the silica produced. Figure 2 shows the behavior of the SSA of silica prepared by process DII at different calcination temperatures and $120 \mathrm{~min}$ of holding time. The silica had to be kept at $1000^{\circ} \mathrm{C}$ for two hours to decrease its specific surface area to approximately $100 \mathrm{~m}^{2} / \mathrm{g}$. Note that calcining at $900{ }^{\circ} \mathrm{C}$ reduces the SSA by only $12.5 \%$ and at $700{ }^{\circ} \mathrm{C}$ by less than $1.0 \%$. The resistance to sintering, as measured by the specific surface area, of silica prepared by process DII can only be attributed to the removal of the alkaline elements and manganese, the main impure elements that can easily react with silica due to its acidic character, promoting sintering.

The literature contains little information on the arrangement of the inorganic compounds in the hull and their chemical bonds with the main organic components - cellulose and lignin. However, some assumptions can be made regarding the reasons why hot water easily reduces the concentration of $\mathrm{K}, \mathrm{Ca}, \mathrm{Mg}$ and $\mathrm{Mn}$. First, no correlation was found between the concentration of calcium and acidic phosphorus or acidic sulfur either before or after the hot water or acid solution treatments, indicating that these elements were not combined in the dry hull as insoluble compounds like calcium sulfate or calcium phosphate. Therefore, the alkaline elements were most probably dispersed in the organic matrix as hydroxides or, perhaps, weakly bonded with lignin or another organic compound. Second, it is known that the potassium concentration is the highest inside vacuoles, a membrane-bound cavity within a cell, often containing a secretion ${ }^{16}$. Therefore, potassium also is not uniformly dispersed in the hull structure, but is present as a soluble compound in the vacuoles of the green rice plant. Hence, there is evidence that silica and these impure elements are not mixed or combined with each other in the dry hull.

\subsection{Processes EI to EIII}

The E processes began by converting the hull to a black fragile body, followed by ball milling to a fine powder with an average particle size of approximately $20.0 \mu \mathrm{m}$. Processes EI, EII and EIII also included treating the black powder or the fragile hull, before firing, with a hydrochloric (acetic or citric) acid solution, with boiling water and with water at room temperature, respectively. The effect of these treatments appeared in the chemical analysis, color and SSA of the produced silica (see Table 2, lines EI to EIII). These results show that, even in the case of the fragile hull, the acid treatment was the most efficient in removing the impure elements in silica black powder while the cold-water

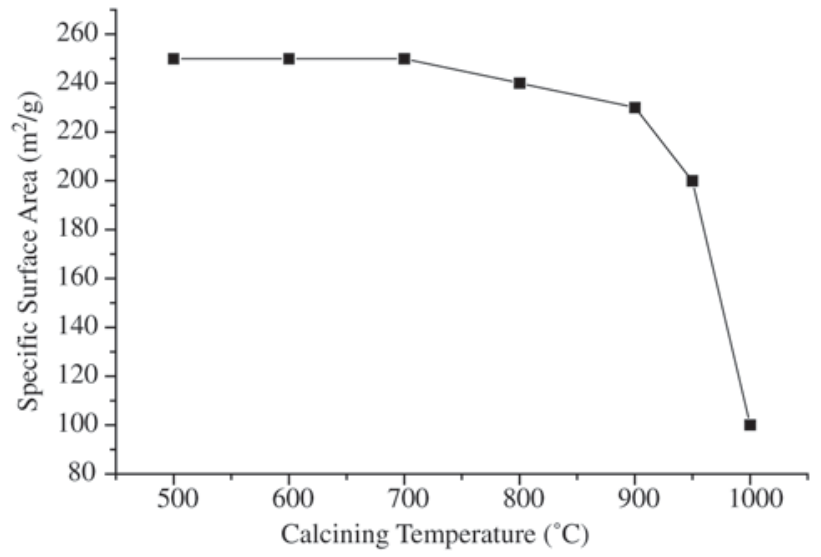

Figure 2. Dependence of the specific surface area on calcining temperature for silica produced by process DII. Calcining time: $120 \mathrm{~min}$.

treatment was the least efficient. The total concentration of the impure elements decreased with the three different treatments; however, the alkaline and alkaline earth elements were more easily removed while comparatively high concentrations of manganese, aluminum and phosphorus/sulfur still remained. These results demonstrate that silica with high SSA can also be prepared by chemical treatment of the black powder to partially remove the main impure elements, $\mathrm{K}$ and $\mathrm{Ca}$, which, in combination with silica, contribute to produce a glassy phase. The white color of the resulting silica indicates (line EI, Table 2) that the concentration of manganese oxide was considerably reduced by the acid treatment, which was confirmed by the chemical analysis. Processes EIV to EX were carried out to compare the effect of the calcination temperature and holding time of the black powder on the properties of the resulting silica. The results of these processes demonstrate that silica with high SSA can be prepared without removing the impure elements before burning, although silica with SSA above $220 \mathrm{~m}^{2} / \mathrm{g}$ could not be prepared by this method. Figure 3 illustrates the effect of the calcining temperature (in this case, $700{ }^{\circ} \mathrm{C}$ and $500{ }^{\circ} \mathrm{C}$ ) and soaking time on the specific SSA of these samples. Decreasing the soaking time, $t$, increases the, SSA, $\Delta(\mathrm{SSA}) / \Delta(\mathrm{t})=0.32 \mathrm{~m}^{2} / \mathrm{g} \cdot \min$ for $\theta=500{ }^{\circ} \mathrm{C}$, while increasing the calcination temperature, q, decreases the SSA, $\Delta(\mathrm{SSA}) / \Delta(\theta)=0.47 \mathrm{~m}^{2} / \mathrm{g}^{\circ} \mathrm{C}$. Acid leaching, at $100^{\circ} \mathrm{C}$, of silica EX, (EX to EXI or EXII) makes silica much purer while moderately increases the SSA.

Table 2, lines EIV to EX, shows the effect of milling the fragile black hulls, before the final burning, for different calcination times, on the SSA of the prepared silica. A comparison of these results with that of process A clearly shows 


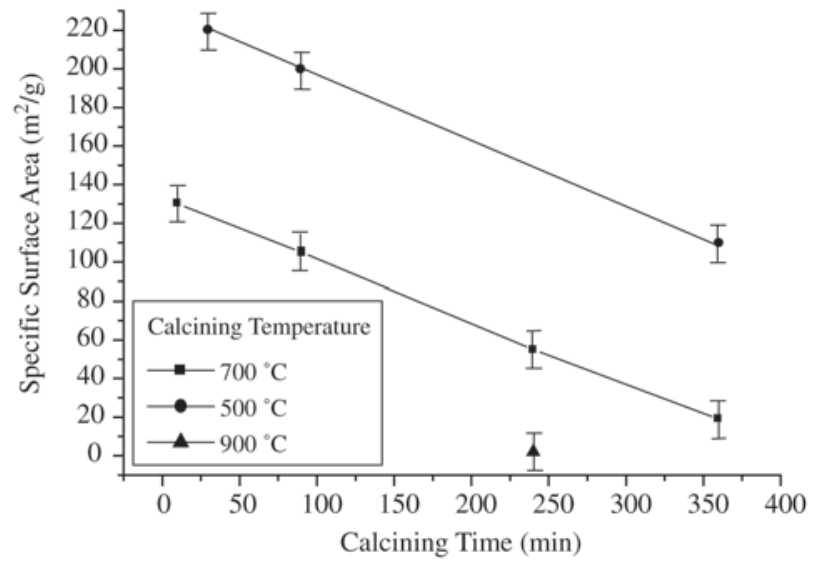

Figure 3. Dependence of the specific surface area on calcining time and temperature for samples prepared by processes E. The triangle refers to process $\mathrm{A}$.

that the preparation of silica with high SSA without prior acid treatment requires the reduction of the fragile hull to a fine powder and an adequate combination of calcination temperature and soaking time. Figure 4 shows the results of additional experiments, carried out at $700{ }^{\circ} \mathrm{C}$ for $360 \mathrm{~min}$, of the effect of the degree of milling the fragile hull on the specific surface area of silica. The SSA increased significantly for black powder particle sizes smaller than $50 \mu \mathrm{m}$.

The effect of precursor particle size on the SSA can be understood as the densification of a ceramic body promoted by a liquid phase ${ }^{12,17}$. The data depicted in Fig. 4 reveals that the amount of impure elements in the $3.0 \mu \mathrm{m}$ particles is insufficient to sinter these small silica particles (see the insert), whose ultimate particles are nanosized. In other words, the liquid phase is not enough to percolate inside the large majority of the $3.0 \mu \mathrm{m}$ silica particles produced from the black powder to promote sintering because of these particles' large specific area, i.e., the silica particles are highly porous. Consider, now, that an unmilled black powder (composed of large particles) consists of the agglomeration of identical $3.0 \mu \mathrm{m}$ particles linked to each other. There is no apparent reason for this system to sinter if these particles contain the same concentration of impurities in each particle, because the relation between the total surface area and the volume of liquid phase would be the same as in a single particle. However, if the impurities are not uniformly distributed, as must be in the raw rice hull, sintering may start in the particle containing the highest concentration of impurities and propagates along the unmilled particle. The chances of finding inhomogeneities in the concentration of impurities increases as the particle size grows. Once a single particle begins to sinter, its liquid phase

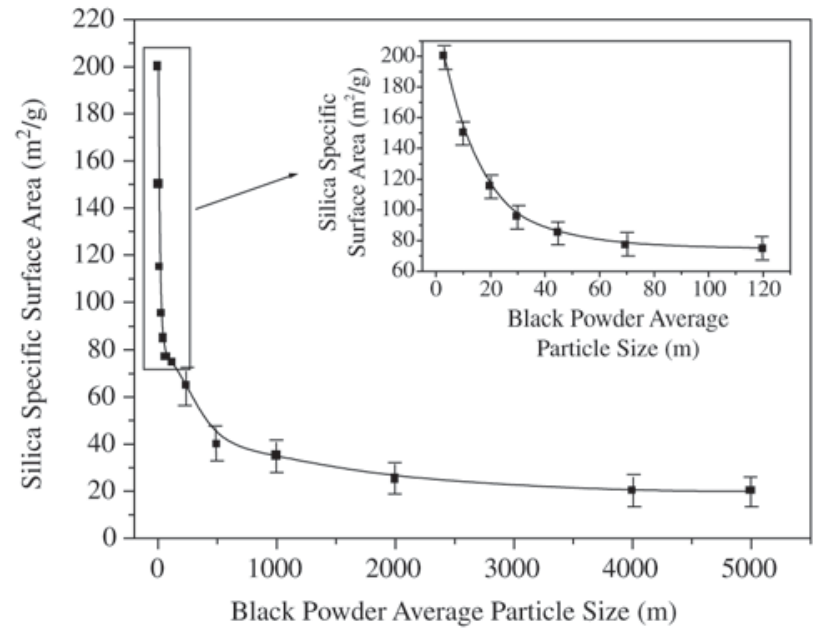

Figure 4. Dependence of the specific surface area of silica on the average particle size of black powder calcined at $700{ }^{\circ} \mathrm{C}$ for $360 \mathrm{~min}$.

spreads out in the neighboring particles, and sintering could then proceed throughout the whole large particle. Based on this assumption, an experiment was carried out in which $3.0 \mu \mathrm{m}$ black powder was isostatically pressed before calcination, producing silica with a low specific surface area after calcination, as was expected. According to Fig. 2, if the impure elements were removed from the black powder, the SSA would not be reduced by calcination at $700{ }^{\circ} \mathrm{C}$; hence, working at temperatures below $800^{\circ} \mathrm{C}$, the only possible way to reduce the SSA of silica produced by processes EIV to EX is by sintering assisted by a liquid phase ${ }^{12}$. It was found that three parameters control the specific area of silica produced by these processes: the particle size of the black powder, the calcination temperature, which controls the viscosity of the glassy phase, and the calcination time, which controls the degree of sintering. Let us now consider the nature of the liquid sintering phase. First, this phase must already be liquid at $700{ }^{\circ} \mathrm{C}$ in order to explain the results of our experiments. Because soda (potash) lime glass fluidizes at much higher temperatures, this type of glass phase is discarded. Also, the impure elements $\mathrm{K}, \mathrm{Ca}$, $\mathrm{Mg}, \mathrm{Na}, \mathrm{Al}, \mathrm{Mn}$ and silica would already have to be mixed to produce this type of glass, which is not usually the case in plants. The most probable composition for the silicate glass phase needs to be close to that of a glaze, richer in $\mathrm{K}_{2} \mathrm{O}$ and $\mathrm{MnO}$ oxides that have high fluxing power ${ }^{18}$. Although the exact composition of the low melting temperature glaze is not known at this time, its amount can be estimated to be larger than $3.5 \mathrm{wt} \%$, a percentage sufficiently high to sinter micrometer sized ceramic particles but insufficient to sinter the silica particle of $10 \mathrm{~nm}$ grains. Krishnarao 
et al. ${ }^{14}$ attribute the sintering of silica burned at $700{ }^{\circ} \mathrm{C}$ to potassium, albeit by a different process.

Our results demonstrate that the impure elements, mono and divalent ions, are more easily acid-leached from the black powder after the first step of processes E than by acid leaching after the burning step (compare line EXII with $\mathrm{C}$ in Table 2), indicating that these elements are already combined after the burning step, most probably with silica in the EXI and EXII process. A comparison of the specific surface areas reveals a more pronounced difference between processes EI and EXII, acidic leaching before and after burning, i.e., before and after the impure elements have reacted with silica.

Silica applications in which purity or color is more important than the SSA require more efficient acid leaching, e.g., leaching in an autoclave at high temperatures or for longer times to remove manganese. When the black powder is milled to a fine powder, as it is done in the E processes, the access of oxygen to the partially burned organic matter is greatly increased; thus, the burning step can be performed in less time if enough air is supplied.

\subsection{Process $F$}

Figure 5 illustrates the result of sodium hydroxide attack on the rice hull. In these experiments, the weight ratio of hull to water was kept constant at $4 \%$ while the molar ratio of silica ( $\approx 19 \mathrm{wt} \%$ of the hull) to $\mathrm{Na}_{2} \mathrm{O}$ varied from 0.3 to 3.2. Both lignin and silica were dissolved but, although the silica was fully dissolved below the ratio of $\mathrm{SiO}_{2} / \mathrm{Na}_{2} \mathrm{O}=2.1$, a large fraction of lignin was still bound to the cellulose structure. The maximum dissolution of lignin, $19.0 \mathrm{wt} \%$ out of the total of $26.0 \mathrm{wt} \%$, was achieved when the $\mathrm{SiO}_{2} / \mathrm{Na}_{2} \mathrm{O}$ ratio was 0.3 . Although this process produces sodium silicate, dissolved lignin is always present. Silica and lignin precipitate simultaneously when the $\mathrm{pH}$ of the filtered solution is reduced to 7.0. One inconvenience, however, compared to the acid attack, is the large loss of organic matter if the hull is destined for burning in a thermoelectric plant.

Hydroxide attack is useful in the conversion of rice hull ash from thermoelectric plants into sodium silicate. The same hull treatment was performed on ash (12 wt \% of carbon and 88 inorganic matter) with a $\mathrm{SiO}_{2} / \mathrm{Na}_{2} \mathrm{O}$ ratio of 2.0 and 1.2. $57 \mathrm{wt} \%$ of the ash was dissolved in the first case and $67 \mathrm{wt} \%$ in the second. After filtering, the silicate solutions were clear, as was the precipitated silica gel, while the manganese impurity remained undissolved together with carbonaceous matter. However, the other impurities present in the hull, such as potassium, were also present in the solution.

It can be concluded that hydroxide attack is not an adequate method to extract silica from rice hulls if the purpose is to produce energy from burning hulls. However, it

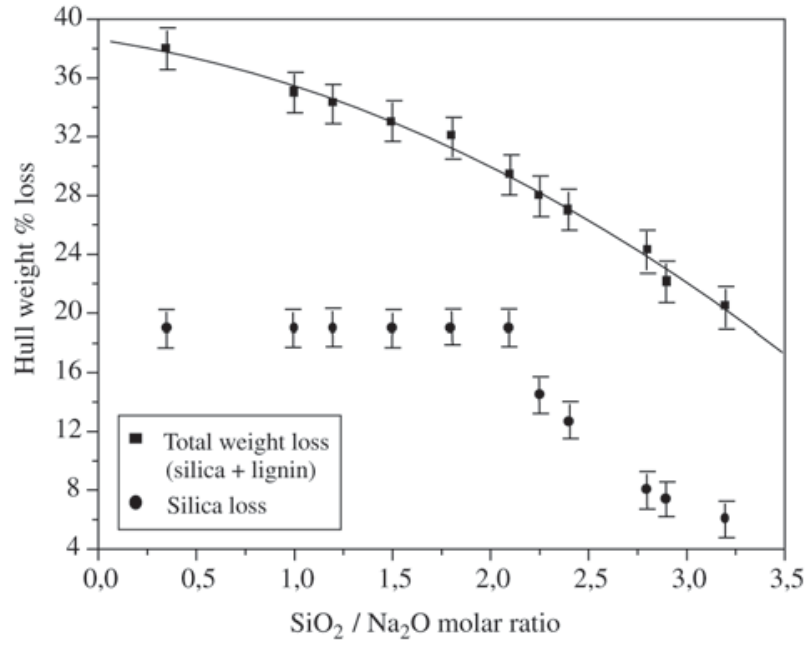

Figure 5. Silica and lignin, in wt $\%$, dissolved from the hull by sodium hydroxide attack at $100^{\circ} \mathrm{C}$, and dependence on the $\mathrm{SiO}_{2} / \mathrm{Na}_{2}$ molar ratio.

is an adequate procedure to produce sodium silicate, a product with a large range of applications, from rice hull ash.

\section{Conclusions}

Rice hulls and straw, when properly preprocessed, can be a useful source of energy and of high quality silica. In the first two methods discussed in this paper, pretreatment with sufficiently hot water or with hot organic acid solutions removes most of the impure elements $(\mathrm{K}, \mathrm{Ca}, \mathrm{Mg}$, $\mathrm{Mn}, \mathrm{Al}$ ) before firing. Although the impure elements are not removed by the third method, high SSA impure silica is produced by controlling three parameters, i.e., reducing the particle size of the precalcined hull, the burning temperature, and the soaking time. Potash-rich silicate glass is proposed to be the liquid phase aid for the sintering of porous particles of nanosilica ultimate particles. The resistance to sintering of the $3.0 \mu \mathrm{m}$ black powder particles results from the nonuniform distribution of the impure elements, mainly potassium, in the hulls. The advantage of the processes discussed in this paper is the direct production of silica in thermoelectric plants; the first two processes allow for the recovery of impurities as fertilizers for rice crops.

Sodium hydroxide attack on the hull proved to be inappropriate because lignin is dissolved simultaneously with the hull's silica. This attack is useful in the production of sodium silicate from rice hull ash produced by thermoelectric plants operating with untreated rice hulls.

\section{Acknowledgments}

This work was made possible through the financial sup- 
port of FAPESP (Brazil). We thank Dr. N. H. Gallo of the IFSC-USP and João Gonzalez of the LIEC/CMDMCUFSCar for their technical support.

\section{References}

1. Houston, D.F. "Rice Hull” p. 301-352, in: Rice Chemistry and Technology, American Association of Cereal Chemists Inc. St. Paul, MN, 1972.

2. Gallo, J.R.; Furlani, P.R.; Bayaglia, O.C.; Hiroce, R. Ciência e Cultura, v. 26, n. 3, 1974.

3. Data provide by IRGA, Rio Grande Institute for Rice, RGS, Brazil.

4. Real, C.; Alcalá, M.D.; Criado, J.M. J. Am. Ceram. Soc., v. 79, n. 8, p. 2012-16, 1996.

5. de Souza, M.F.; Batista, P.S.; Regiani, I.; Libório, J.B.L.; de Souza, D.P.F.; Mat. Res. v. 3, n. 2, p. 25-30, 2000.

6. Amick, J.K. J. Electrochem. Soc., v. 129, p. 864-866, 1982.

7. Hanna, S.B.; Farag, L.M.; Mansourt, N.A.L. Thermochimica Acta, v. 81, n. 77, 1984.

8. de Souza, M.F.; Batista, P.S.; Liborio, J.B.L. Brazilian Patent PI 9903208, 1999.
9. Zhang, R.; Zhang, Z. Biosource Technology, p. 235-245, 68, 1999.

10. Rohatagi, K.; Prasad, S.V.; Rohatagi, P.K. J. Mater. Sci. Lett., v. 829, n. 6, 1987.

11. Vogel, W. Chemistry of Glass, pg.101, American Ceramic Soc. Columbus, Ohio, 1985.

12. Ring, T.A. Fundamentals of Ceramic Powder Processing and Synthesis, pg 844-863, Academic Press, San Diego, 1996.

13. Frequent characteristic found in the hull burned in thermoelectric plants operating at temperatures above $1000{ }^{\circ} \mathrm{C}$. See also references 7 and 14 .

14. Krishnarao, R.V.; Subrahmanyan, J.; Jagadish Kumar, T. J., Eur. Ceram. Soc., v. 21, p. 99-104, 2001.

15. Iler, R.K. "The Chemistry of Silica", John Wiley and Sons, Inc. NY, NY, 1979.

16. Personal communication, P.R. Furlani, Analytical Chemistry Laboratory, Instituto Agronômico de Campinas, IAC, São Paulo, Brazil.

17. Jujiu, T.; Messing, G.L. J. Non-Crystalline Solids, v. 143, p. 133-139, 1992.

18. Grimshaw, R.W. The Chemistry and Physics of Clay, Ernest Benn Limited, London, 1971. 